\title{
MARGINAL GAP DISTANCE AND FRACTURE RESISTANCE OF LITHIUM DISILICATE AND ZIRCONIA-REINFORCED LITHIUM DISILICATE ALL-CERAMIC CROWNS CONSTRUCTED WITH TWO DIFFERENT PROCESSING TECHNIQUES
}

\author{
Shereen M. El Sayed * and Zeinab N. Emam*
}

\begin{abstract}
Statement of problem: The microstructure and processing methods used to produce any dental restoration might affect the final mechanical outcomes as well as the clinical success.

Objectives: The purpose of this study was to evaluate the fracture resistance of lithium disilicate and zirconia reinforced lithium disilicate ceramic crowns constructed using two processing techniques after fatigue loading namely, CAD/CAM technique and pressing technique. The marginal integrity of the crowns was examined before and after fatigue loading.
\end{abstract}

Methods: A total number of thirty-two freshly extracted maxillary first molars were collected. The teeth were chosen to be of similar bucco-lingual and mesiodistal dimensions. The teeth were mounted vertically into epoxy resin templates. Full coverage all-ceramic preparation was performed for all samples using a standardized technique. The prepared teeth were randomly divided into four equal groups $(n=8)$ according to the all-ceramic materials and technique used for crown fabrication as follows: Group I: IPS e-max $\mathrm{CAD}(\mathrm{EC})$ : eight prepared teeth were restored with machinable lithium disilicate glass ceramics. Group II: Celtra Duo(CD): eight prepared teeth were restored with machinable zirconia-reinforced lithium disilicate glass ceramics. Group III: IPS e-max Press (EP): eight prepared teeth were restored with pressable lithium disilicate glass ceramics. Group IV: Celtra Press (CP): eight prepared teeth were restored with pressable zirconia-reinforced lithium disilicate glass ceramics. The crowns were cemented using self-adhesive resin cement (Rely X Unicem). Vertical margin gap distance of all the crowns was measured using a stereomicroscope. Following vertical marginal gap distance measurements, the samples were subjected to fatigue cyclic loading for 60000 cycles which is equivalent to six months clinical service. The vertical marginal gap distance for all samples were subsequently remeasured after the fatigue loading testing. Fracture resistance test was done using universal testing machine. The fracture load was recorded in Newton. Data was collected, tabulated and statistically analyzed.

* Associate Professor, Fixed Prosthodontics Department, Faculty of Dentistry, Cairo University, Egypt, Associate Professor, Fixed Prosthodontics Division, Oral and Maxillofacial Department, Faculty of Dentistry, Umm Al-Qura University. 
Results: One-way ANOVA test for comparison between the fracture resistance of the four types of all-ceramic crowns revealed that there was a statistically significant difference between mean fracture resistance of different all ceramic materials and techniques used in this study $(P$-value $<0.001)$. For the marginal gap distance either before or after fatigue cyclic loading; there was a statistically significant difference between the four all ceramic crowns used in this study.

Conclusions: $\mathrm{CAD} / \mathrm{CAM}$ techniques showed better fracture resistance values than pressable techniques, even if the same material was used. The addition of zirconia to lithium disilicate ceramics did not improve the fracture resistance of all ceramic crowns. Pressable processing techniques showed better vertical marginal gap distance than CAD/CAM techniques for both ceramic materials used. Cyclic loading resulted in significant increase in the vertical marginal gap distance for all ceramic crowns using different processing techniques.

KEYWORDS: Lithium disilicate, Zirconia-reinforced lithium disilicate, crowns, fatigue loading, marginal gap distance, fracture resistance, Celtra Duo, Celtra Press, E.max Press, E.max CAD.

\section{INTRODUCTION}

Nowadays, the increased demand for esthetic rehabilitation of missing tooth tissue has led to the growing popularity of all ceramic systems. The type of the ceramic material and the technique of processing used are considered to be important factors that increase the range of indications in the field of restorative dentistry, prosthodontics, and dental implantology. Thus, the decision to select the correct material from different options according to the indications has become interesting and more widely covered. ${ }^{(1)}$

CAD/CAM technology has become a common alternative to the conventional processing methods. ${ }^{(2)}$ This processing method in conjunction with the continuous expansion of all ceramic materials used with this technique resulted in perfect understanding and aid in the clinician's selection process. ${ }^{(3)}$

Another commonly used processing technique is the heat pressing technique used to construct the pressable ceramic restorations that has become successfully used since long time. Glass ceramic ingots are heated so that the ceramic material is allowed to flow under pressure into a mold formed using lost wax technique. ${ }^{(4)}$

An important area of interest in the ceramic materials is the group of the glass-ceramics which are widely used long time ago ${ }^{(5,6)}$. The continuous development in their mechanical properties, enhanced microstructure and different processing techniques have made them an attractive unique group ${ }^{(7)}$.Since the introduction of the lithium disilicate glass-ceramic group (IPS emax , Ivoclar, Vivadent) and its fabrication to a reach a full-contour monolithic restorations along with cementation using adhesive resin cement, it proves to be suitable option in higher stess situations ${ }^{(8)}$.

Even though the great acceptance and the wide use of the lithium disilicate glass ceramics, a new addition to this category of ceramics was invented; through the introduction of zirconia-reinforced lithium silicates; glass ceramics reinforced with polycrystalline ceramics ${ }^{(1,3,8)}$.

The addition of $10 \%$ weight zirconia to the lithium silicate ceramic has led to a newly designed ceramic containing lithium silicate as the main crystalline phase in a vitreous matrix reinforced with zirconium oxide crystals which act as nucleating agent ${ }^{(9,10)}$, reinforcing the ceramic structure by crack interruption. ${ }^{(6)}$

Zirconium dioxide in the Celtra Duo(Dentsply, Sirona) is entirely diluted in the amorphous glass, thus, creating uniform fine-grained structure with a mean size of $0.5-1 \mu \mathrm{m}$ nucleated lithium silicate crystals. On the contrary, lithium disilicate crystals 
found in lithium disilicate glass ceramics is six times larger than this size ${ }^{(3,11)}$. The manufacturer offered Celtra Duo in a fully crystallized state and it can be hand-polished or glaze-fired before delivery. The result is a ceramic structure with improved mechanical properties ranging between 370 and $420 \mathrm{MPa}^{(12)}$, the maximum strength will be reached upon oven glazing for zirconia-reinforced lithium silicates and oven crystallization for conventional lithium disilicates ${ }^{(3)}$. Moreover, this ceramic structure offers good optical, milling and polishing properties due to the presence of high percentage of glass matrix. These advantages attracted the clinicians and become the most popular for chairside restorations ${ }^{(3)}$.

As was previously mentioned, the technique of processing is a critical factor that may affect the final restoration's strength and marginal integrity. ${ }^{(4)}$ Both groups of lithium silicates (IPS E-max CAD) and zirconia-reinforced lithium silicates (Celtra Duo) are available as machinable CAD blocks for $\mathrm{CAD} / \mathrm{CAM}$ technique as well as press-fit ingots for pressable technique (IPS Emax Press and Celtra press).

Celtra press was introduced as a recent technical alternative to machinable Celtra Duo blocks to allow for fabrication of multi-unit bridges as well as inlays ,onlays, veneers and single restorations as it provides higher mechanical properties than Celtra Duo $^{(13,14)}$

Thus, the aim of this study was to evaluate the fracture resistance of IPS e-max crowns and Celtra crowns after fatigue loading, constructed using two processing techniques; The $\mathrm{CAD} / \mathrm{CAM}$ technique and the pressing technique. The marginal integrity of the crowns was examined before and after fatigue loading.

Null hypothesis was that the fracture resistance and the vertical marginal gap distance of molar crowns will not be affected by the type of the ceramic material or the processing technique.

\section{MATERIALS AND METHODS}

\section{Teeth selection and preparation:}

A total number of thirty two freshly extracted maxillary first molars were collected. The selected teeth were inspected for absence of caries, restorations or cracks. The teeth were chosen to be of similar bucco-lingual and mesiodistal dimensions; these dimensions were measured at the cemento-enamel junction, height of contour and the occluso-axial line angles in millimeters using digital caliper $(0-50 \mathrm{~mm}, 0.01 \mathrm{~mm}$, Germany). The selected teeth were cleaned and disinfected in $0.5 \%$ sodium hypochlorite solution, then stored in distilled water for maximum one month until the experiment began.

The roots of the selected teeth were serrated with a disc for retention. The teeth were mounted vertically into epoxy resin mounting templates (Polypoxy 700, polymer, chemical industries for construction Co., CIC, Egypt). The cemento-enamel junction of each tooth is adjusted to be higher than the top of the template by $1 \mathrm{~mm}$. Full coverage allceramic preparation was performed for all samples using a standardized technique. The teeth were prepared using high-speed handpiece (Midwest Dentsply, Desplaines, IL) connected to a surveyor (Degussa F1; Degudent, Hanau, Germany) to obtain a standardized preparation. The preparation was designed with $1.5 \mathrm{~mm}$ deep chamfer finish line placed $1 \mathrm{~mm}$ above the cemento-enamel junction. The axial surfaces were prepared with a $6^{\circ}$ angle from the vertical axis of the tooth to achieve a total convergence angle of $12^{\circ}$. The mesiodistal and buccolingual dimensions of the prepared teeth were measured at 3 different levels circumfrencially to assure a standardized diameter in all prepared teeth. All teeth used in this study were prepared by the same operator.

\section{Sample grouping:}

The prepared teeth were randomly divided into four equal groups ( $n=8)$ according to the all-ceramic 
materials and techniques used for crown fabrication as follows:

Group I: IPS e-max CAD (EC): eight prepared teeth were restored with machinable lithium disilicate glass ceramics.

Group II: Celtra Duo (CD): eight prepared teeth were restored with machinable zirconia-reinforced lithium disilicate glass ceramics.

Group III: IPS e-max Press (EP): eight prepared teeth were restored with pressable lithium disilicate glass ceramics.

Group IV: Celtra Press (CP): eight prepared teeth were restored with pressable zirconia-reinforced lithium disilicate glass ceramics. The chemical composition and manufacturers of the materials used in this study are presented in table (1).

\section{All-Ceramic crowns fabrication}

All the prepared teeth assigned for groups I, II were scanned using inLab scanner (InEos,
Sirona, Germany). E-max CAD and Celtra Duo crowns were constructed using CAD/CAM system software (InLab SW4.0, Sirona) for designing and CAD/CAM milling machine (Cerec-inLab MC XL, Sirona, Germany) for milling. The parameters for IPS e-max CAD and Celtra Duo crowns were designed to be as follows: axial wall thickness of $1.5 \mathrm{~mm}, 2 \mathrm{~mm}$ thickness of the occlusal surface at the cusp tip, $1.5 \mathrm{~mm}$ thickness of the occlusal surface at the central fossa, and $50 \mu \mathrm{m}$ cement thickness. Following the milling procedures, the IPS e-max CAD crowns (Group I) were crystallized in Programat furnace (Programat P500, Ivoclar, Vivadent, Schann, Lieichtenstein) at $850^{\circ}$ for thirty minutes. Regarding Celtra Duo crowns (Group II), the crowns were examined for their fit on each corresponding tooth after milling, followed by polishing of the occlusal surface using diamond stones and rubber polishers (Celtra Polishing kit, Dentsply, Germany) according to manufacturer's instructions at low speed and minimum pressure.

TABLE (1): The chemical composition and manufacturers of the materials used in this study.

\begin{tabular}{|c|c|c|}
\hline Material & Composition & Manufacturer \\
\hline IPS e-max CAD & $\begin{array}{l}\mathrm{SiO}_{2}, \mathrm{Li}_{2} \mathrm{O}, \mathrm{K}_{2} \mathrm{O}, \mathrm{P}_{2} \mathrm{O}_{5}, \mathrm{ZrO}_{2}, \mathrm{ZnO}, \mathrm{Al}_{2} \mathrm{O}_{3}, \mathrm{MgO}, \\
\text { pigments }\end{array}$ & Ivoclar Vivadent Schaan Liechtenstein \\
\hline Celtra Duo & $\mathrm{SiO}_{2}, \mathrm{Li}_{2} \mathrm{O}, \mathrm{ZrO}_{2}, \mathrm{P}_{2} \mathrm{O}_{5}, \mathrm{Al}_{2} \mathrm{O}_{3}, \mathrm{~K}_{2} \mathrm{O}, \mathrm{CeO}_{2}$, pigments & Dentsply; Konstanz, Germany \\
\hline IPS e-max Press & $\begin{array}{l}\mathrm{SiO}_{2}, \mathrm{Li}_{2} \mathrm{O}, \mathrm{K}_{2} \mathrm{O}, \mathrm{P}_{2} \mathrm{O}_{5}, \mathrm{ZrO}_{2}, \mathrm{ZnO} \text {, other oxides and } \\
\quad \text { ceramic pigments }\end{array}$ & $\begin{array}{l}\text { Ivoclar Vivadent, } \quad \text { Schaan } \\
\text { Liechtenstein }\end{array}$ \\
\hline Celtra Press & $\begin{array}{l}\mathrm{SiO}_{2}, \mathrm{Li}_{2} \mathrm{O}, \mathrm{ZrO}_{2}, \mathrm{P}_{2} \mathrm{O}_{5}, \mathrm{Al}_{2} \mathrm{O}_{3}, \mathrm{~K}_{2} \mathrm{O}, \mathrm{CeO}_{2} \text {, other oxides } \\
\quad \text { and pigments }\end{array}$ & Dentsply;Konstanz, Germany \\
\hline Rely X Unicem & $\begin{array}{l}\text { Powder: } \\
\text { - Alkaline (basic) fillers } \\
\text { - Silanated fillers } \\
\text { - Initiator components } \\
\text { - Pigments } \\
\text { Liquid: } \\
\text {-Methacrylate monomers containing phosphoric acid } \\
\quad \text { groups } \\
\text { - Methacrylate monomers } \\
\text { - Initiator components } \\
\text { - Stabilizers }\end{array}$ & $\begin{array}{l}3 \mathrm{M}^{\mathrm{TM}}, \mathrm{ESPE}^{\mathrm{TM}}, \\
\text { Germany }\end{array}$ \\
\hline
\end{tabular}


As for groups III, IV;IPS e-max press and Celtra press, the teeth were scanned using the same inLab scanner that was used for construction of groups I, II crowns. Virtual wax up was digitally designed and milled using the same parameters that was adjusted for groups I, II. This was done to assure standardization of the samples between the four tested groups. Eight IPS e-max pressable all-ceramic crowns and eight Celtra press all-ceramic crowns were constructed using heat pressing technique by the aid of the previously constructed milled wax crowns. The CAD/CAM milled wax crowns were sprued and invested in IPS Press Vest investment material (Ivoclar, Vivadent) for group III or Celtra press investment material (Dentsply, Sirona) for group IV and the crowns were pressed in IPS e-max CAD pressable ceramic or Celtra press ceramic according to manufacturer's instructions. Following pressing, devesting was done using airborne particle abrasion $\left(50 \mu \mathrm{m} \mathrm{Al}_{2} \mathrm{O}_{3}\right.$ at 1 bar, $\left.30 \mathrm{PSI}\right)$. Finishing was done using fine diamond disc and grinding instruments according to manufacturer's instructions.

The fitting surfaces of the crowns were etched using 5\% hydrofluoric acid gel (IPS Ceramic etching gel, Ivoclar, Vivadent) for 20 seconds then rinsed thoroughly. Silane coupling agent (Calibra, Silane, Dentsply) was applied to the dried fitting surfaces of the crowns, allowed to soak for 60 seconds, then dried using air stream. The surfaces of the prepared teeth were treated with $37 \%$ solution of phosphoric acid for 15 seconds, then rinsed with water and dried. The crowns were cemented using self-adhesive Rely X Unicem (3M, ESPE) resin cement according to manufacturer's instructions. A static load of $3 \mathrm{Kg}$ was applied on the occlusal surface of the cemented crowns using a specially designed loading device. The excess cement was removed, and light curing was done from each surface for 20 seconds using light curing unit (Mini
LED, $1250 \mathrm{mw} / \mathrm{cm}^{2}$, Satelec, Acteon). The load was applied for 10 minutes.

\section{Vertical marginal gap distance measurments}

Vertical margin gap distance of all crowns was measured using an image analysis system. This method uses image analysis software (Image J-1b, USA) in combination with a stereomicroscope (Olympus, SZ-PT: Japan) ${ }^{(15)}$

For all samples, Fourpoints were marked with an indelible marking pen in the middle of the buccal, lingual, mesial and distal surfaces of the crowns. Two added marks for each surface were marked 2 $\mathrm{mm}$ mesial and distal to the middle points to obtain a total of twelve measuring points for each crown.

For each crown, the area of interest was captured by CCD digital camera (DP-10 Olympus, Japan) mounted on the stereomicroscope. The vertical margin gap distance between the cervical margin of the crowns and the finish line was assessed at the previously marked points. These readings were calculated using the image analysis software.

\section{Cyclic fatigue loading}

Mechanical aging was performed using a programmable equipment; the newly developed four stations multimodal ROBOTA chewing simulator integrated with thermo-cyclic protocol (Model ACH-09075DC-T, GERMANY).

The specimens were embedded in Teflon housing in the lower sample holder. A weight of 10 $\mathrm{kg}$, which is comparable to $100 \mathrm{~N}$ of chewing force was exerted. The test was repeated 60000 times to clinically simulate 6 months chewing condition, according to previous study. ${ }^{(16)}$

The vertical marginal gap distance for all samples were subsequently remeasured after the fatigue loading testing using the same method described previously. 


\section{Fracture resistance testing}

All samples were individually mounted on a computer-controlled material testing machine (Model 3345; Instron Industrial Products, Norwood, MA, USA) with $5 \mathrm{kN}$ loadcell and data were documented using computer software (Instron ${ }^{\circledR}$ Bluehill Lite Software). Samples were secured to the lower fixed compartment of testing machine by tightening screws. Fracture test was done by compressive mode of load applied occlusally using a metallic rod with spherical tip (5.8 $\mathrm{mm}$ diameter) attached to the upper movable compartment of testing machine traveling at cross-head speed of $1 \mathrm{~mm} / \mathrm{min}$ with tin foil sheet in-between to achieve homogenous stress distribution and minimization of the transmission of local force peaks. The load required to fracture was recorded in Newton.

\section{Statistical Analysis}

Data were presented as mean, standard deviation (SD), median and range values. For parametric data; one-way Analysis of Variance (ANOVA) was used to compare between the four ceramics. Bonferroni's post-hoc test was used for pair-wise comparisons when ANOVA test is significant. For non-parametric data; Kruskal-Wallis test was used to compare between the four ceramics. Dunn's test was used for pair-wise comparisons when Kruskal-
Wallis test is significant. Wilcoxon signed-rank test was used to study the effect of cyclic fatigue on each ceramic. The significance level was set at $\mathrm{P} \leq 0.05$. Statistical analysis was performed with IBM SPSS Statistics for Windows, Version 23.0. Armonk, NY: IBM Corp.

\section{RESULTS}

\section{Fracture resistance}

The mean, standard deviation (SD) values and results of one-way ANOVA test for comparison between the fracture resistance of the four types of all ceramic materials revealed that there was a statistically significant difference between mean fracture resistance of different all ceramic materials used in this study ( $P$-value $<0.001$, Effect size $=0.896)$. There was no statistically significant difference between e.max CAD and Celtra Duo; both showed the statistically significantly highest mean fracture resistance while for IPS e.max Press and Celtra Press; both showed the statistically significant lowest mean fracture resistance. (Fig. 1, table 2)

\section{Marginal gap distance}

As regard to the total marginal gap distance either before or after fatigue cyclic loading; there

TABLE (2) The mean, standard deviation (SD) values and results of one-way ANOVA test for comparison between fracture resistance for the four all-ceramic materials used.

\begin{tabular}{|c|c|c|c|c|c|c|c|c|c|}
\hline \multicolumn{2}{|c|}{ IPS e.max CAD } & \multicolumn{2}{c|}{ Celtra Duo } & \multicolumn{2}{c|}{ IPS e.max Press } & \multicolumn{2}{c|}{ Celtra Press } & \multirow{2}{*}{ P-value } & \multirow{2}{*}{$\begin{array}{c}\text { Effect size } \\
\text { (Eta squared) }\end{array}$} \\
\cline { 1 - 7 } Mean & SD & Mean & SD & Mean & SD & Mean & SD & & 0.896 \\
\hline $1857.9^{\mathrm{A}}$ & 163.3 & $1779.8^{\mathrm{A}}$ & 169.8 & $980.1^{\mathrm{B}}$ & 78.9 & $1084^{\mathrm{B}}$ & 137.1 & $<0.001^{*}$ & 0.1 \\
\hline
\end{tabular}

*: Significant at $P \leq 0.05$, Different superscripts are statistically significantly different. 
was a statistically significant difference between the four different ceramic types $(P$-value $<0.001$, Effect size $=0.653)$ and $(P$-value $<0.001$, Effect size $=$ $0.656)$, respectively. Pair-wise comparisons between ceramic types revealed that there was no statistically significant difference between IPS e.max CAD and Celtra Duo; both showed the statistically significant highest mean marginal gap distances, Whereas IPS e.max Press and Celtra Press; both showed the statistically significantly lowest mean marginal gap distances. Table (3)
The total marginal gap distance with all types of ceramics; namely IPS e.max CAD, Celtra Duo, IPS e.max press and Celtra press, there was a statistically significant increase in mean marginal gap distance after cyclic fatigue $(P$-value $<0.001$, Effect size $=0.876),(P$-value $<0.001$, Effect size $=0.869),(P$-value $<0.001$, Effect size $=0.875)$ and $(P$-value $<0.001$, Effect size $=0.875)$, respectively. (Fig.2, table 4).

TABLE (3) Descriptive statistics and results of Kruskal-Wallis test for comparison between marginal gap distances of the four ceramics.

\begin{tabular}{|c|c|c|c|c|c|}
\hline \multirow{2}{*}{\multicolumn{2}{|c|}{ Ceramic }} & \multicolumn{2}{|c|}{ Before cyclic fatigue } & \multicolumn{2}{|c|}{ After cyclic fatigue } \\
\hline & & Mean (SD) & Median (Range) & Mean (SD) & Median (Range) \\
\hline \multirow{4}{*}{$\begin{array}{l}\text { Marginal } \\
\text { gap } \\
\text { distance }\end{array}$} & IPS e.max CAD & $37.8(6.7)^{\mathrm{A}}$ & $38.8(21.4-45.8)$ & $60.8(9.2)^{\mathrm{A}}$ & $56.7(47.1-78.6)$ \\
\hline & Celtra Duo & $36.9(8.8)^{\mathrm{A}}$ & $35.4(11.2-49.6)$ & $65.7(9)^{\mathrm{A}}$ & $64.1(47.1-87.1)$ \\
\hline & IPS e.max Press & $21.2(4.7)^{\mathrm{B}}$ & $21.8(9.1-28.1)$ & $35.3(8)^{\text {в }}$ & $33.4(25.8-63.5)$ \\
\hline & Celtra Press & $19(4.4)^{\text {в }}$ & $18.8(13-30)$ & $39.4(9.3)^{\text {в }}$ & $37.2(31.9-69.8)$ \\
\hline \multicolumn{2}{|c|}{$\mathrm{P}$-value } & \multirow{2}{*}{\multicolumn{2}{|c|}{$\begin{array}{c}<0.001 * \\
0.653\end{array}$}} & \multirow{2}{*}{\multicolumn{2}{|c|}{$\begin{array}{c}<0.001 * \\
0.656\end{array}$}} \\
\hline \multicolumn{2}{|c|}{ Effect size (Eta Squared) } & & & & \\
\hline
\end{tabular}

*: Significant at $P \leq 0.05, \quad$ Different superscripts in the same column within each group indicate statistically significant difference between ceramic types

TABLE (4). Descriptive statistics and results of Wilcoxon signed-rank test for comparison between marginal gap distances before and after cyclic fatigue.

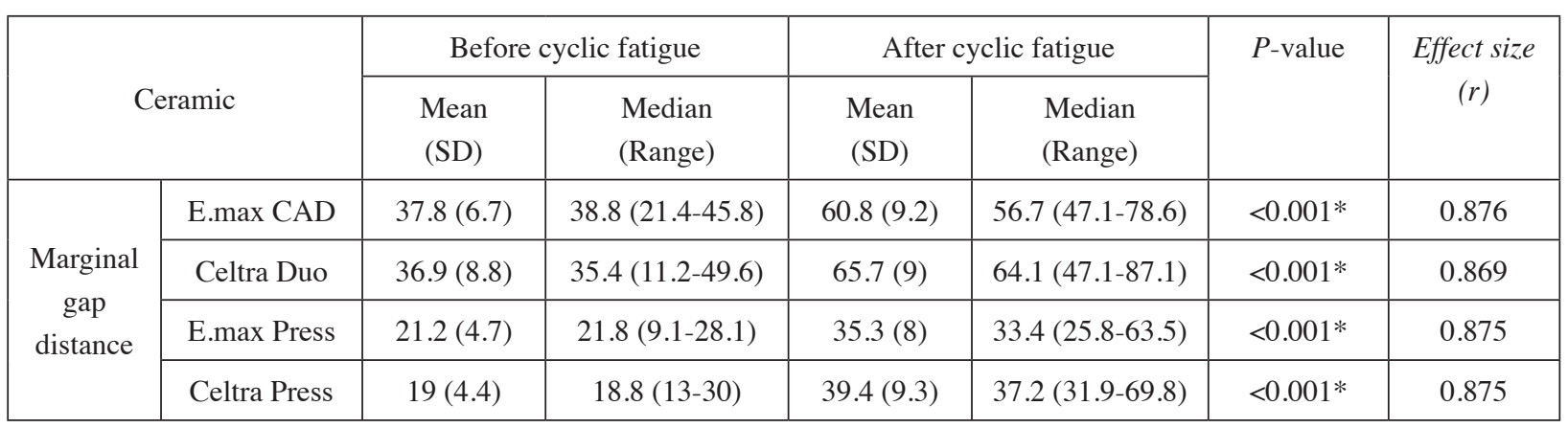

\footnotetext{
*: Significant at $P \leq 0.05$
} 


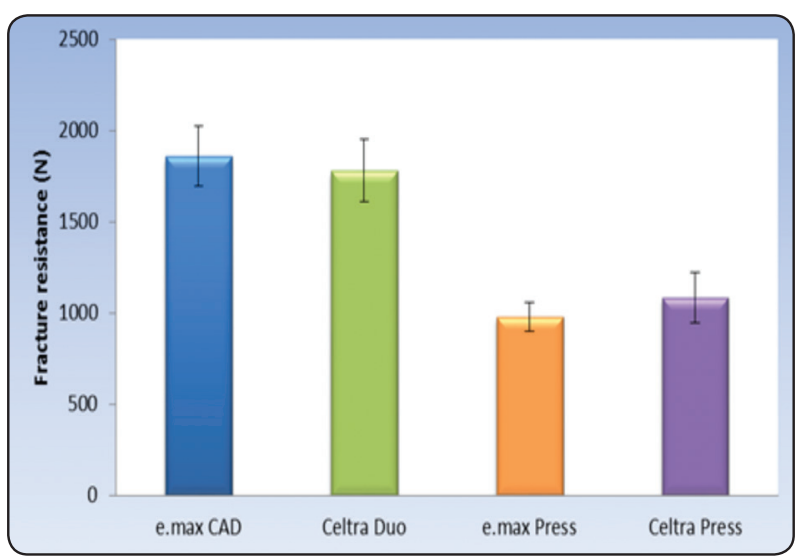

Fig. (1). Bar chart representing mean and standard deviation values for fracture resistance for the four all ceramic materials.

\section{DISCUSSION}

Patients' needs and expectations towards metalfree esthetic restorations have resulted in the remarkable widespread use of all-ceramic systems. Ceramics have proven its efficiency as biologically compatible and highly esthetic material ${ }^{\cdot(2,16)}$

Lithium disilicate ceramics and its new modified class known as zirconia reinforced lithium silicate have gained a great popularity owing to their high fracture resistance and superior esthetic properties making them very strong alternative for a wide range of clinical situations. ${ }^{(17,18)}$ Along with the $\mathrm{CAD} / \mathrm{CAM}$ technology, the heat pressing technique has been used for construction of this class of ceramics with the advantages of decreased porosity, increased flexural strength and excellent marginal fit. ${ }^{(19)}$ Hence, selecting the appropriate ceramic material with the proper processing technique has become the choice of the clinicians in every clinical condition to be able to have a long term successful ceramic restoration. ${ }^{(20,21)}$

Based on the results of this study, the null hypothesis that the fracture resistance and the vertical marginal gap distance of molar crowns will not be affected by the type of the ceramic material or the processing technique was rejected. Regarding the fracture resistance testing, the results of the

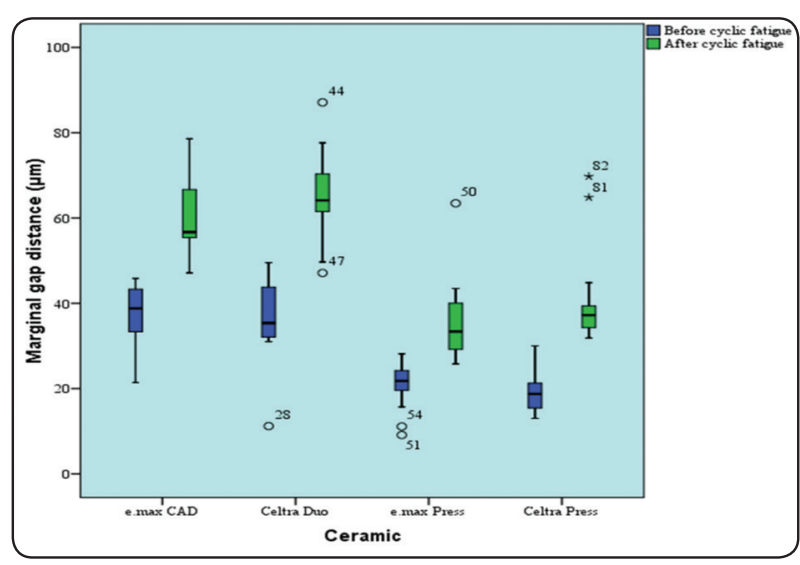

Fig. (2) Box plot representing marginal gap distance in different groups before and after cyclic fatigue (Circles and stars represent outliers)

present study revealed that there was no statistically significant difference between mean fracture resistance values of IPS e.max CAD and Celtra Duo; where both showed statistically significant highest mean fracture resistance. This was in accordance with Preis et al ${ }^{(22)}$ who examined the fracture resistance of lithium disilicate and zirconia reinforced lithium disilicate and they found that both have similar values. The high fracture resistance values of e-max CAD were reasonable due to the development of the high crystalline content of fine highly-interlocking lithium disilicate crystals embedded in the glassy matrix after crystallization. Taha et al ${ }^{(6)}$ stated that through the post milling crystallization, the controlled growth of the grain size $(0.5-5 \mu \mathrm{m})$ gives rise to the final form of this glass ceramic with enhanced flexural strength of 360 $\mathrm{MPa}$. Additionally, Guazatto et al ${ }^{(23)}$, attributed the increase in the flexural strength of e-max CAD to the introduction of tangential compressive stresses within the material resulting in crack deflection and subsequent resistance to crack propagation. Sagsoz et al ${ }^{(24)}$ and Apel et al ${ }^{(25)}$ stated that the same explanation in their previous studies. On the other hand, the newly tested Celtra Duo material gives comparable results to e-max CAD material. The incorporation of $10 \%$ zirconia which is completely dissolved in the glass phase proposing homogenous 
ultrafine crystalline microstructure provides this material with high strength. ${ }^{(6,26,27)}$ It was expected that addition of zirconia to lithium disilicate ceramics will improve their fracture resistance, however, they give almost the same results. Badawy et al (28) reported that the ultrafine nano-sized glass ceramic crystals confined inside zirconia and/or alumina would create subgrain boundaries allowing an easy fast processing and giving Celtra Duo reduced flaw size and increased strength. On the contrary to this explanation, their in-vitro study revealed lower flexural strength of Celtra Duo when compared with IPS e-max CAD. ${ }^{(28)}$

It is significant to mention that according to the manufacturer's instructions, Celtra Duo is supplied in a fully crystallized ceramic block and the manufacturer offers two choices for the processing techniques; either to mill and polish or to mill and fire. ${ }^{(6,10)}$ In this study, the authors preferred to choose the first processing technique to be able to test one of the advantages of the Celtra Duo ceramics which is the easy fast time saving process without any further processing after milling. This may give an explanation to the comparable unexpected fracture resistance mean values of Celtra Duo in comparison to IPS e-max CAD. The selection of the mill and fire processing technique might have given enhanced fracture resistance values to Celtra Duo crowns.

Even if a material has similar chemistry and microstructure, the processing technique might have improved or deteriorated the final strength and clinical serviceability of the ceramic material. The results of this study proved this through comparing the mean fracture resistance values of the pressable groups; e-max press and Celtra press and the CAD/ CAM groups; e-max CAD and Celtra Duo, where the authors found that CAD/CAM groups have statistically significant higher mean values than the pressable groups. The use of external pressure at high temperatures to allow sintering is the technique of construction of pressable ceramics. ${ }^{(12)}$ Hallmann et $\mathrm{al}^{(19)}$, discussed the properties of heat pressed glass ceramics in their previous study and reported that changes in mechanical properties for materials with identical chemical compositions are mainly due to their microstructure.

The results of the mean fracture resistance values of e-max press and Celtra press showed no statistically significant difference. This was in accordance with Ap el et al ${ }^{(29)}$, who concluded that the addition of zirconia to glass matrix of lithium disilicate did not increase the flexural strength owing to the increase in viscosity due to $\mathrm{ZrO}_{2}$ content and the accompanied decrease in crystal growth.

It is noteworthy to mention that the use of human teeth might have caused some degree of variability in the results due to complexity in standardization, although the preparation of the teeth was done using milling machine. The cementation of the anatomical crowns to natural dentin using adhesive bonding had made a clinical simulation as this factor would affect the actual fracture resistance values ${ }^{(30)}$

The assessment of the vertical marginal gap distance is considered one of the most important parameters that influenced the long-term service of ceramic restorations. (6) A proper marginal fit is important to prevent dissolution of the cement resulting in plaque accumulation and subsequent caries, pulpal affection and increase in stress concentration that may lead to fracture of restoration later.

The results of this study showed that the machinable ceramics; IPS e.max CAD and Celtra Duo had statistically significantly higher mean vertical marginal gap distance values than pressable groups; IPS e.max press and Celtra press. This may be due to the pressure exerted from the milling instrument and the resistance of the material itself which might have resulted in marginal fractures. This is very common with brittle materials like ceramics. Zimmermann et al, ${ }^{(31)}$ reported that the glass matrix is brittle and ceramic crystallites may be easily disrupted if the pressure of the milling instrument 
is applied. On the contrary, the pressing technique allow better compressibility and flowability of the material during pressing, especially with smaller crystals found in Celtra press ceramic. ${ }^{(32)}$

The IPS e.max CAD and Celtra Duo ceramics revealed no statistically significant difference in vertical marginal gap distance values. The same results were provided in the in vitro study done by Taha et al. ${ }^{(6)}$

In this study, cyclic loading was applied to all samples to test the ceramic performance under clinically simulating conditions. It was well known that recurrent stresses occurring during function may lead to subcritical crack growth in brittle ceramic material which will affect the mechanical behavior and the marginal fit. ${ }^{(33)}$ There was a statistically significant increase in the vertical marginal gap distance values after cyclic fatigue loading with all types of ceramics used in this study. This agreed with several in vitro studies ${ }^{(6,34)}$ which concluded that the repeated masticatory forces will lead to deterioration of the marginal fit.

It is important to mention that the results of the vertical marginal gap distance for all ceramics used in this study are within the clinically acceptable standards of $120 \mu \mathrm{m}$ even after cyclic loading.

Further investigations are needed to examine the fracture resistance and marginal fit of zirconia reinforced lithium disilicate(Celtra Duo) after firing rather than polishing for the final restoration. Further investigation is needed to examine the effect of different cement type and technique on the marginal fit and fracture resistance.

\section{CONCLUSIONS}

Within the limitation of this study, the following conclusions were drawn:

- CAD/CAM techniques showed better fracture resistance values than pressable techniques, even if the same material was used.
- The addition of zirconia to lithium disilicate ceramics did not improve the fracture resistance of all ceramic crowns.

- Pressable processing techniques showed better vertical marginal gap distance than CAD/CAM techniques for both ceramic materials used.

- Cyclic loading resulted in significant increase in the vertical marginal gap distance for all ceramic types and processing techniques.

\section{REFERENCES}

1. Spitznagel FA, Boldt J, Gierthmuehlen PC. CAD/CAM ceramic restorative materials for natural teeth. J Dent Res 2108;97(10):1082-91

2. Goujat A, Abouelleil H, Colon P, Jeannin C, Pradelle N, et al. Marginal and internal fit of CAD-CAM inlay/onlay restorations: a systematic review of in vitro studies. J Prosthet Dent 2019;121:590-7.

3. Fasbinder DJ.A review of chairside CAD/CAM restorative materials. J Cosmetic Dent 2018;34(3):64-74.

4. Giordano R, McLaren E. Ceramics overview: classification by microstructure and processing method. Compendium 2010;31(9):682-97.

5. Silva LH, Lima E, Miranda RB, Favero SS, Lohbauer U, Cesar PF. Dental ceramics : a review of new materials and processing methods. Braz Oral Res 2017;31(suppl):133-45

6. Taha D, Wahsh M. Assessment of marginal adaptation and fracture resistance of endocrown restorations utilizing different machinable blocks subjected to thermomechanical aging. J Esthet Restor Dent 2018;30:319-28

7. Anusavice KJ, KAkar K, Ferree N. Which mechanical and physical testing methods are relevant for predicting the clinical performance of ceramic-based dental prostheses? Clin Oral Implants Res 2007;18(3):218-31.

8. McLaren EA, Figueira J. Updating classifications of ceramic dental materials: a guide to material selection. Compendium 2015;36(6):739-45

9. Kern M, Sasse M, Walfart S. Ten-year outcome of threeunit fixed dental prostheses made from monolithic lithium disilicate ceramic. J Am Dent Assoc. 2012;143(3):234-40.

10. Choi S, Yoon HI, Park EJ. Load-bearing capacity of various $\mathrm{CAD} / \mathrm{CAM}$ monolithics molar crowns under recommended occlusal thickness and reduced occlusal thickness conditions. J Adv Prosthodont 2017;9:423-31 . 
11. Belli R, Wendler M, deLigny D, Cicconi MR, Petschelt A, Peterlik H, et al. Chairside CAD/CAM materials. Part 1: measurement of elastic constants and micro-structureal characterization. Dent Mater 2017;33(1):84-98.

12. Thillaigovindan R, Rai R, Mishal S, Priya S. Recent Advances in ceramics- a review. World J Pharm Res 2019; $8(2): 515-24$.

13. Matsuzaki F, Sekine H, Honma S, et al. Translucency and flexural strength of monolithic translucent zirconia and porcelain layered zirconia. Dent Mater 2015;34:910-7.

14. Elsaka SE, Elnaghy AM. Mechanical properties of zirconia reinforced lithium silicate glass ceramic. Dent Mater 2016;32:908-14.

15. Hamza T, Al-Baili M, Abdel-Aziz M. Effect of artificially accelerated aging on the marginal fit and color stability of laminate veneers. Stomatological Dis Sci 2018;2:1-7.

16. Nawafleh N, Hatamleh M, Elshiyab S and Mack F, Lithium Disilicate Restorations Fatigue Testing Parameters: A Systematic Review Journal of Prosthodontics 2016; 25:116-126.

17. Peumans M, Valjakova EB, De Munck J, Mishevska $\mathrm{CB}$, Meerbeek BV. Bonding effectiveness of luting composites to different CAD/CAM materials. J Adhes Dent 2016;18:289-302.

18. Fasbinder DJ, dennison JB, Heys D, Neiva G. A clinical evaluation of chairside lithium disilicate $\mathrm{CAD} / \mathrm{CAM}$ crowns: a two-year report. J Am Dent Assoc 2010; 14(2):10-14.

19. Hallmann L, Ulmer P, Gerngross MD, Jetter J, Mintrone M, Lehmann F, Kern M. Properties of hot-pressed lithium silicate glass-ceramics. Dent Mater 2019;35:713-29.

20. Valjakova EB, Stevkovska VK, Kapusevska, Gigovski N, Misevska CB, Grozdanov A. Contemporary dental ceramic materials, A review: Chemical composition, physical and mechanical properties, indications for use. J Med Sciences 2018;6(9):1742-1755.

21. Meng H, Xie H, Yang L, Chen B, Chen Y, Zhang H. Effects of multiple firings on mechanical properties and resin bonding of lithium disilicate glass-ceramic. J Mech Behav of Biom Mater 2018;88:362-369

22. Preis V, Behr M, Hahnel S, Rosentritt M. Influence of cementation on in vitro performance, marginal adaptation and fracture resistance of CAD/CAM-fabricated ZLSmolar crowns. Dent Mater 2015;31:1363-9.
23. Guazzato M, Albakry M, Ringer SP, Swain MV. Strength , fracture toughness and microstructure of a selection of all-ceramic materials. Part 1. Pressable and alumina glass infiltrates ceramics. Dent Mater 2004;20:449-56.

24. Sagsoz O, Yildiz M, Hojjat Ghahramanzadeh As, Alsaran A. In vitro fracture strength and hardness of different CAD/CAM inlays. Niger J Clin Pract 2108;21:380-7.

25. Apel E, Deubner J, Bernard A, Holand A, Muller R, Kappert $\mathrm{H}$, et al. Phenomena and mechanisms of crack propagation in glass ceramics. J Mech Behav Biomed Mater 2008;1:313-25.

26. Lien W, Roberts HW, Platt JA, et al. Microstructural evolution and physical behavior of a lithium silicate glassceramic. Dent Mater 2015;31(18):928-40.

27. Helvey GA. The expansion of millable materials-new additions to the market increase patient-care options. Inside Dental Technol 2014;5:1.

28. Badawy R, El-Mowafy O, Tam L. Flexural properties of chairside CAD/CAM materials. Dent Med Probl 2016;53(2):230-5.

29. Apel E, Hoen C, Rheinberger V, Holland W. Influence of $\mathrm{ZrO}_{2}$ on the crystallization and properties of lithium disilicate glass-ceramics derived from a multi-component system. J Eur Ceram Soc 2007;27:1571-7.

30. Chang CY, Kuo JS, Lin YS, Chang YH. Fracture resistance and failure modes of CEREC endo-crowns and conventional post and core-supported CEREC crowns. J Dent Sci 2009;4(3):110-7.

31. Zimmermann M, Valcanaia A, Neiva G, Mehl A, Fasbinder D. Three-dimensional digital evaluation of the fit of endocrowns fabricated from different CAD/CAM materials. 2019;28:504-9.

32. Celtra Press, Dentsply Sirona, Directions for use brochure. www.celtra-Dentsplysirona.com

33. Gungor MB, Nemli SK. Fracture resistance of CAD-CAM monolithic ceramic and veneered zirconia molar crowns after aging in a mastication simulator. J Prosthet Dent 2018;119:473-80.

34. Rosentritt M, Sikora M, Behr M, Handel G. In vitro fracture resistance and marginal adaptation of metallic and toothcolored post systems. J Oral Rehabil 2004;31(7):675-81. 